\title{
Socio-economic Factors Affecting Soil Fertility Management Practices in Gindeberet Area, Western Ethiopia
}

\author{
Lechisa Takele $^{1 *}$, Achalu Chimdi ${ }^{2}$ and Alemayehu Abebaw ${ }^{1}$ \\ ${ }^{1}$ Department of Chemistry, College of Natural and Computational Sciences, Ambo University, PO Box: 19, \\ Ambo, Ethiopia \\ ${ }^{2}$ College of Computational and Natural Sciences, Wollega University, P.O Box: 395, Nekemte, Ethiopia
}

\begin{tabular}{ll}
\hline \multicolumn{1}{c}{ Abstract } & Article Information \\
\hline In order to design more appropriate research and development programs geared towards & Article History: \\
improving integrated nutrient management practices, understanding farmer's knowledge is & Received : $15-12-2014$ \\
indispensable. However, little effort has been made to capture and characterize the indigenous & Revised \\
knowledge of farmers in Ethiopia. This study was carried out with the objective of to assess & Accepted : 25-02-2015 \\
\cline { 2 - 2 } soil fertility and land use management practices in Gindeberet area, Western Ethiopia. & Keywords: \\
Household questionnaire was used as tool for data collection. A total of 86 households were & Socio-economy \\
interviewed. About 90\% of farmers perceive that the current level of soil fertility as low and & Soil fertility management \\
82\% perceived that soil fertility will continue to decline. Farmers use inorganic and organic & Gindeberet \\
\cline { 2 - 2 } fertilizers for soil fertility improvement. The majority of farmers (98\%) prefer to use inorganic & \multirow{2}{*}{ *Corresponding Author: } \\
fertilizers. High price was mentioned as the main factor limiting use of inorganic fertilizer. The & Lechisa Takele \\
result clearly indicates that land use changes and its associate management have significant & \\
influence on soil fertility. Therefore, there is an imperative need to develop sustainable soil & E-mail: \\
management options that will minimize the effect of land use change on soil fertility. & lechisat@gmail.com \\
Copyright@2015 STAR Journal, Wollega University. All Rights Reserved. & \\
\hline
\end{tabular}

\section{INTRODUCTION}

Soil fertility is declining in many parts of sub-Saharan Africa (Stoorvogel et al., 1993). One of the major constraints to crop production faced by smallholder subsistence farmers is the inadequate supply of nutrients (Quinones et al., 1998; Shapiro and Sanders, 1998). Farmers are either entirely abandoning the traditional practice of using natural fallow to restore soil fertility, or are unable to leave land fallow for long enough for it to be effective. The use of mineral fertilizers is declining as they are increasingly beyond the means of most small-scale farmers (Larson et al, 1996). Erosion and severe run-off are further depleting existing soil nutrient reserves, while levels of soil organic matter are declining as land is subject to over-use.

Land degradation and soil nutrient depletion have become serious threats to agricultural productivity in subSaharan Africa. Most arable lands have been affected by degradation thereby reducing agricultural productivity, which in turn results in poor economic growth of countries (Bekele, 2003).Ultimately this results in abject poverty and high incidences of food insecurity among the population that depend on agriculture for livelihood. The continued threat to land resources is exacerbated by the need to reduce poverty and poor farming practices, especially among smallholder farmers.

One of the biophysical constraints to increasing agriculture productivity is the low fertility of the soils
(Bekunda et al., 1997). Improving soil fertility levels has become an important issue in development agendas because of its linkage to food insecurity and economic well being of the population (Mitiku, 1996; Ajayi et al., 2003).

The use of inorganic fertilizers as an option for improving soil fertility and productivity, has immediate results, but is unaffordable for most farmers. In spite of the growing awareness of low cost soil fertility technologies, the rate of adoption and continued use of the technologies remain limited. Experiences of agroforestry show that, though there is much interest in agro forestry among farmers, adoption rates are still low. The study seeks to understand factors that influence farmer's choices of the different soil fertility improvement technologies (Donova, 1996).

\section{MATERIALS AND METHODS}

\section{Description of the Study Area}

The study is situated in GindeBeret District, West Shewa Zone of Oromiya National Regional State, Ethiopia, between astronomical grids of $9^{0} 21^{\prime}$ to $9^{0} 50^{\prime} \mathrm{N}$ and $37^{\circ} 37^{\prime}$ to $38^{\circ} 08^{\prime} \mathrm{E}$ (PEDOWS, 1997). The district town, Kachisi $\left(9^{0} 32^{\prime} \mathrm{N}\right.$ and $\left.37^{\circ} 49^{\prime} \mathrm{E}\right)$ is geographically located approximately at the centre of the District 193 $\mathrm{Km}$ West of Addis Ababa (Figure 1). 


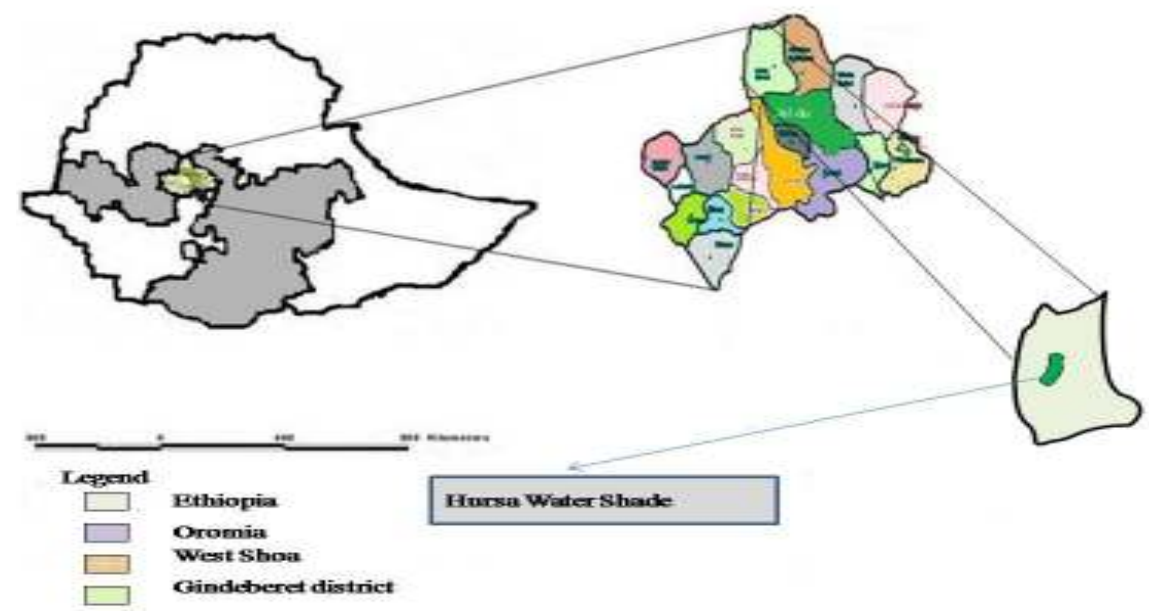

Figure 1: Location map of study area

Ten years trends of rainfall distribution showed that there was no even distribution of rainfall in each year. Rather it was highly fluctuated between the ranges of 882-
$2039 \mathrm{~mm}$. the same is true for temperature and varied from 21 to 25.9 and 5.6 to $9.2^{\circ} \mathrm{C}$ for the maximum and minimum temperature respectively (Figure 2 ).

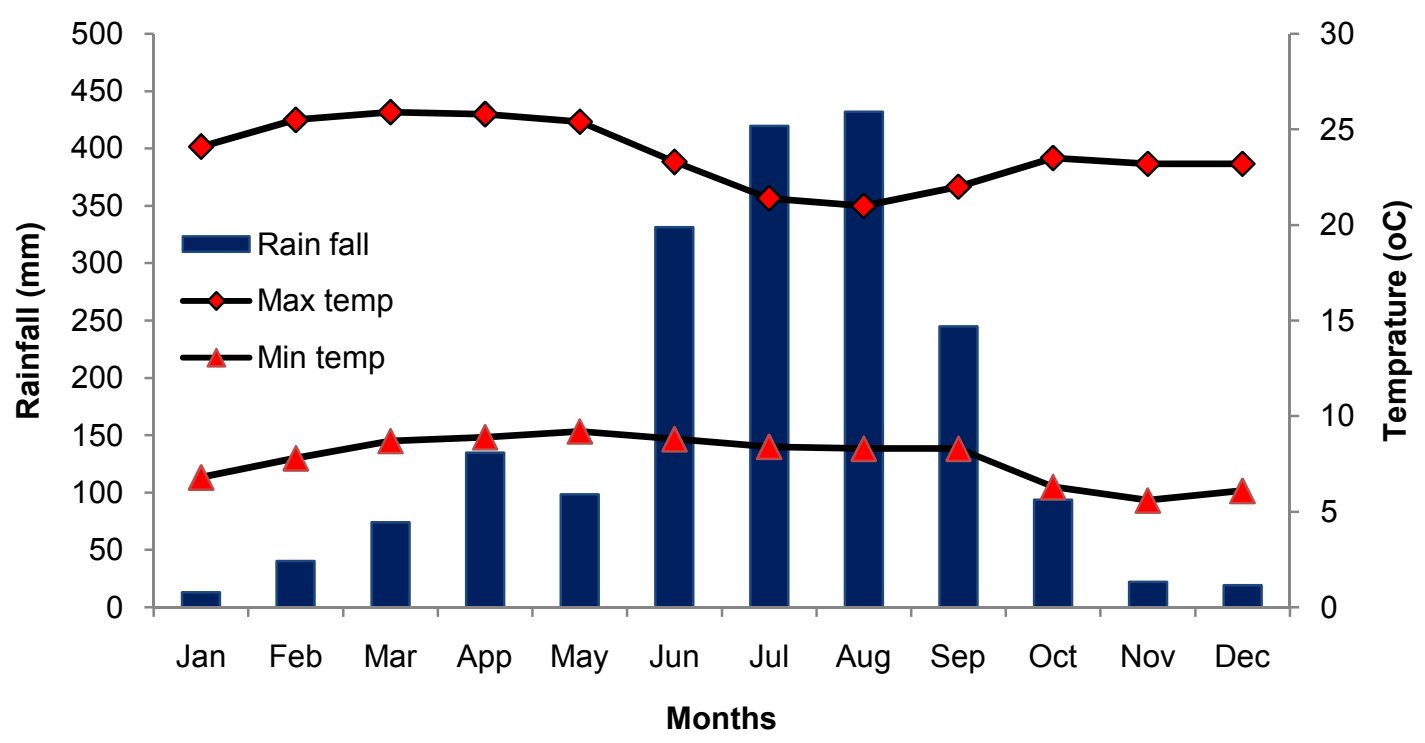

Figure 2: Mean monthly rainfall and mean maximum and minimum temperatures of the study area

\section{Survey of Socio Economic Factors}

A survey was conducted to determine the socio economic condition that affect different land use management practices and soil fertility. First the total numbers of the population and total number of households of the study area were registered from the available secondary sources. The number of sample household selected for the interview was determined by using the formula developed by Kothari (2004).

\section{Data Analysis}

Qualitative data generated by open and closed ended questionnaires and informal discussions were analyzed using descriptive statistics such as frequencies, tables and percentages.

\section{RESULTS AND DISCUSSION}

Farmers Soil Erosion and Soil Nutrient Management Practices

Soil erosion was the most common and severs problems of the study area. Data collected showed that about $75.5 \%$ of the respondent's answered the problems of soil erosion while $18.42 \%$ respondents answered sedimentation and $6.18 \%$ respondents answered both erosion and sedimentation as the main problems of the area (Figure 3).

Survey result revealed that, farmland affected by erosion was higher as compared to the farmland affected by sedimentation and both. Erosion problems interrelated with farmland management practices and topographic nature of the landscapes.

Majority of the farmers respond that, the occurrences of rill erosion was the dominant erosion rate $40(46.5 \%)$ on their farmland (Figure 3 ) gully erosion was also reported by $15(17.4 \%)$ of farmers along their farmlands. On the other hand about $10(11.6 \%), 12(14 \%)$ and $9(10.5 \%)$ respondents perceived sheet erosion, sedimentation and both sedimentation and erosion as problems respectively. 


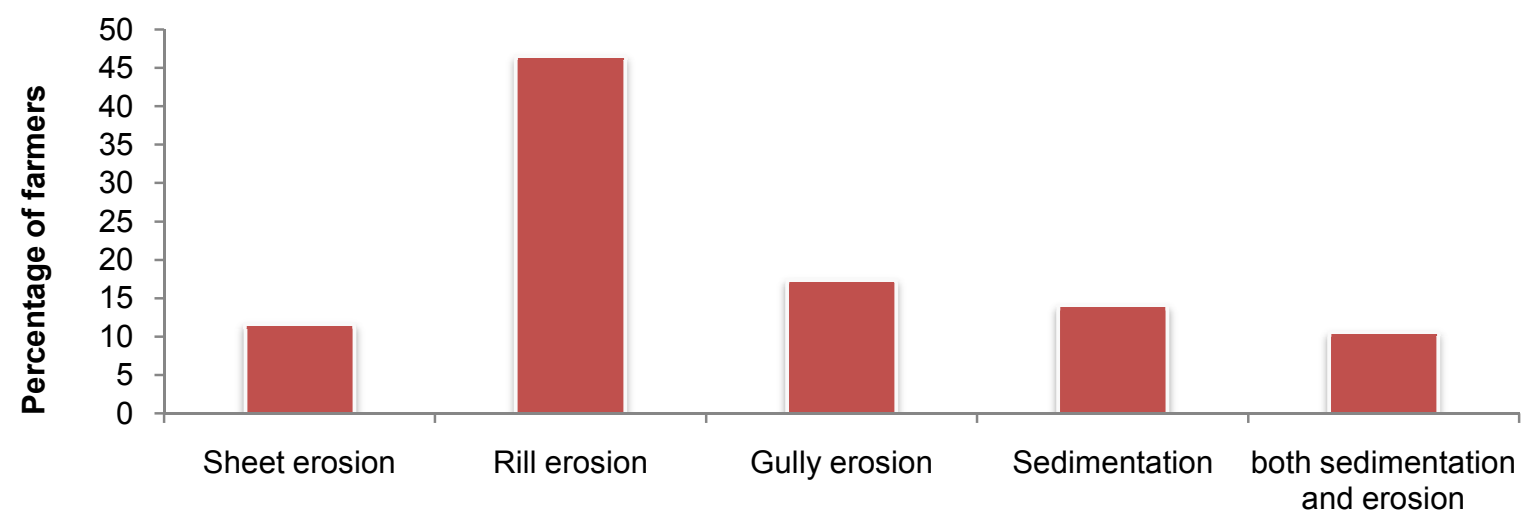

\section{Farm problems}

Figure 3: Farmer's trends on soil erosion and sedimentation problems

On the other hand, farmers were not widely adopted to take erosion protection measures in the study area. Data presented in Figure 4 showed that farmers who did soil protection measures in order to maintain soil erosion were very less in percentages. The population percentage who took soil protection measures were $12(14 \%)$ terracing while $8(9.3 \%)$ and $7(8.1 \%)$ were practiced ditching and contour planting respectively. In contrast to these 59 $(68.6 \%)$ of respondents did not attempt to protect their farmland. Farmers traditionally constructed terraces to improve soil fertility and productivity; Terraces slow down water runoff and capture sediments. Farmers regard these sediments as fertile soil material, and believe that terracing can make an infertile soil more fertile. This shows that they see soil fertility as a dynamic characteristic of soils, and not as an inherent quality in itself

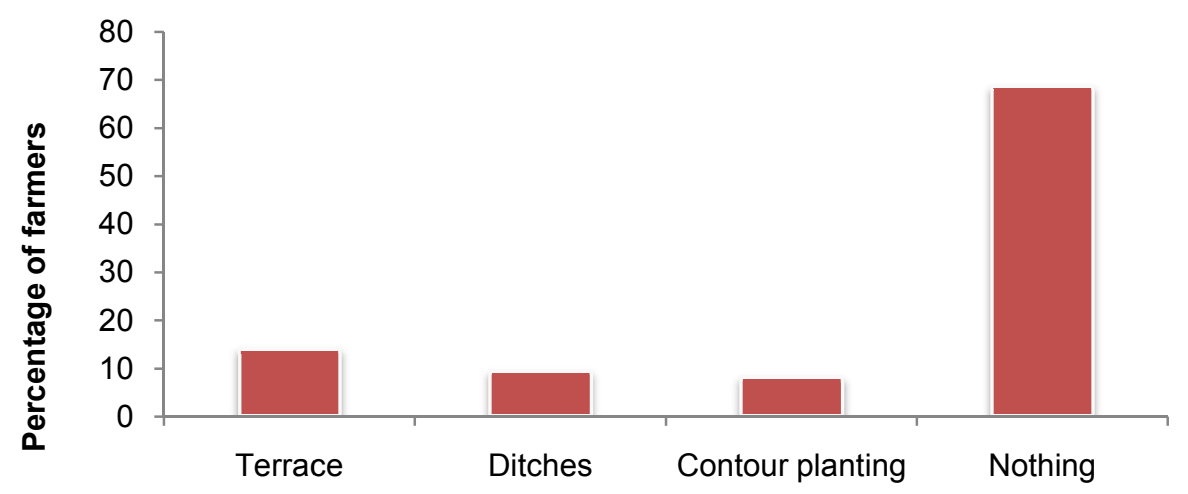

\section{Protection measures}

Figure 4: Erosion control methods practiced in the study area

Based on the survey data, the reasons why farmers have not taken protection measures was due to lack of knowledge, finance and man power in order to take proper protection measures.

\section{Farmer's Perception of Soil Fertility Problems}

Understanding the soil fertility problems from farmer's point of view is crucial in analysis of the adoption potential of soil fertility improvement technologies. Farmers will adopt technologies that contribute positively to their livelihood. Hence, if soil fertility problems are viewed critical for their livelihood; farmer's likelihood for adoption is enhanced. Farmers possess a lot of knowledge about the trend of soil fertility in the study area. Farmers over 40 years of age were asked to describe the soil fertility changes over the years, $90 \%$ described the soil fertility levels are declining as compared to 20 years ago. About $10 \%$ of the farmers describe that the soil fertility levels are improving with the introduction of new technologies, such as, agro-forestry.

Decline in soil fertility caused low agriculture production and productivity. Fertilizer was introduced to increase agriculture production to meet the consumption needs of the growing population, which was making extensive agriculture practice impossible. However over the years, fertilizer prices have become costly for smallholder farmers, making it difficult for farmers to apply the recommended rate, at the appropriate time and annually. Therefore, farmers continue to cultivate on the plots leading to continued decline in soil fertility and crop production. Farmers also claim that continued use of inorganic fertilizer reduce the soil fertility and agriculture production. This could be attributed to the decline in organic matter in the soil, which besides supplying nutrients, ensures good soil conditions necessary for plant growth. 
The majority of farmers are aware of the soil fertility problems, as $90 \%$ of the interviewed farmers perceive the current level of soil fertility as low, while $6.75 \%$ believe that the soil fertility is still manageable whilst only

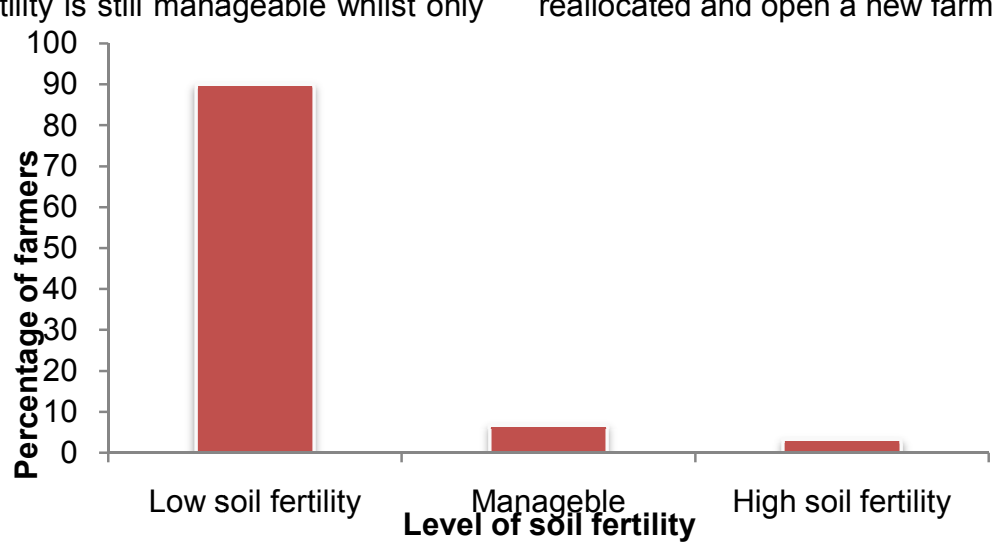

Figure 4: Farmer's perception of the current soil fertility level
$3.25 \%$ perceive the fertility in their farms as still high (Figure 5). Farmers that perceive soil fertility levels as high have either access to inorganic fertilizer or just reallocated and open a new farming plot.
According to the farmers, continued cultivation on the same piece of land without fallowing over the years has led to declining soil fertility for most farm plots. Although farmers are aware of the soil fertility problems in the area, farmers continue to cultivate and overexploit the available natural resources with little input, in order to meet household consumption needs. Most farmers (82\%), therefore, perceived that soil fertility will continue to decline. However, $6 \%$ of the farmers perceive that soil fertility will increase whilst $12 \%$ perceive that there will be no changes at all (Figure 5). Introduction of the low cost, organic soil fertility improvement technologies gives farmers an option for resorting soil organic matter and improve fertility levels.

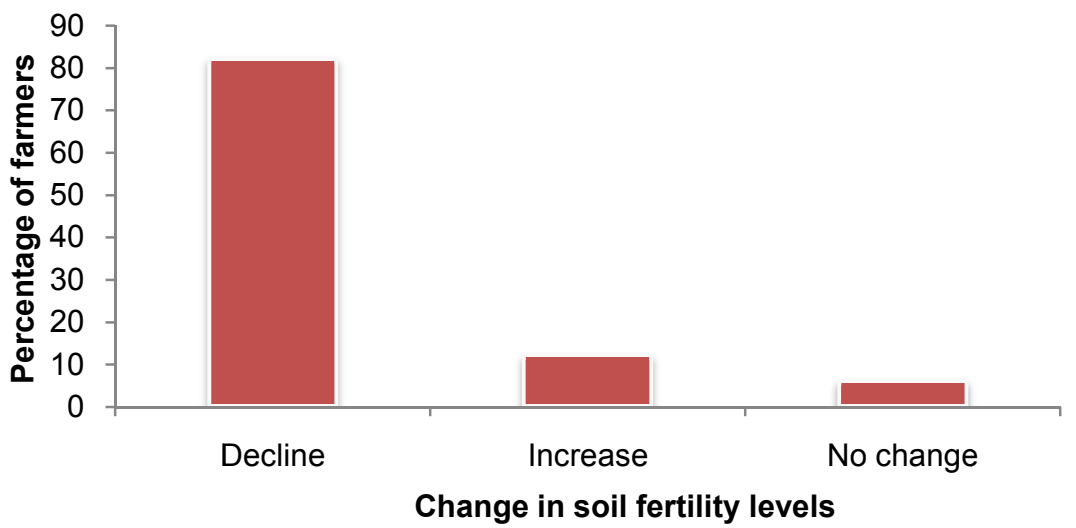

Figure 5: Farmer's perceived future changes in soil fertility levels

Continuous cropping with little or no mineral inputs was expressed as one of the causes for declining soil fertility by $88 \%$ of the farmers. Farmers have been cultivating on the same farm land continuously for years without rest, therefore soils have been mined of the nutrients and the soils ability to produce high crop yield has declined. Soil erosion, deforestation and increase in population, were other factors that farmers noted that contributed to loss of soil fertility. This shows that farmers are knowledgeable of the soil fertility problems, the causes and the resulting effect on agriculture production and food security. Hence, farmers are willing to invest in measures that will maintain and improve soil fertility.

\section{Soil Fertility Management Practices}

In order to improve agriculture production and food security with regard to the existing soil fertility problems, farmers have adapted a range of soil fertility improvement technologies. Figure 6 , shows the percentage use for various technologies.

Inorganic fertilizer has immediate effects on crop production; therefore a good option for improving soil fertility. Household use of inorganic fertilizers however is determined by their capacity to meet the increasing inorganic fertilizer prices. Data showed in (Figure 6) almost all farmers $(98.54 \%)$ in the study area use inorganic fertilizers with other amendments to maintain fertility of their land. But among the users of inorganic fertilizers majority of them did not apply sufficient amount to their lands. This is because; the majority of farmers using inorganic fertilizers do not have access to credit due to, lack of credit facilities, fear of not being able to pay back and not meeting the criteria. Farmers purchase inorganic fertilizer from their own savings, remittances or other off farm activities.

Manure is an important input for maintaining and enhancing soil fertility. Data collected from survey showed that, about $10.86 \%$ of farmers use manure to maintain fertility of their lands. The use of animal dung, ash and household trash to crop land is common practice to improve soil fertility as manuring. In the present study area, this is well manifested in the homestead gardening or at backyards. But, Manure tends to be used only by a few number farmers, who apply it to small areas around 
Lechisa Takele et alo,

the homesteads this is due to, the relatively small number of livestock per household; Dung is often used as fuel and they also believed that, applying manure to the fields increases the number of weeds in the fields.

Crop rotation is very important, as a shortage of $\mathrm{N}$ is one of the most common causes of crops not growing well. Plant nutrients specially $\mathrm{N}$ which has been removed by crop harvest or lost from soil by erosion must be replenished by incorporating $\mathrm{N}$ fixing leguminous crop in cropping sequences for better yield. Crop rotations are not widely practiced by sampled households only practiced by
Sci. Technol. Arts Res. J., Jan-March 2015, 4(1): 149-153

$12.01 \%$ (Figure 6 ). All of sampled farmers who practiced crop rotations on their fields were cultivated for annual crops with a common rotation sequences; Teff-beanfinger millet and Noug (Niger seed) one after the other. Teff and finger millet are considered as soil depleting crops and bean and Noug are legumes and enrich soil fertility. It is a long year's farmer's experiences in which legume crops were rotating with other non-leguminous crops for the main purposes of soil fertility improvement in the study areas. The use of crop rotation helps to increase soil organic matter, reduce erosion and bring biological diversity back to the soil.

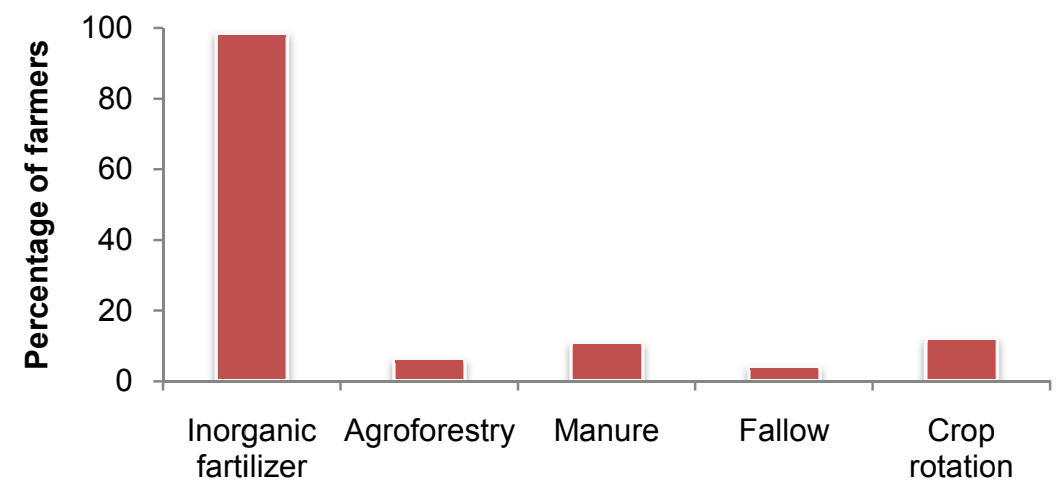

Soil fertility improvment technologies

Figure 6: Percentage of farmers using different soil fertility improvement technologies

The traditional method of restoring soil productivity is fallowing. The decision to leave a field fallow is not a matter for an individual farmer to decide on. It is agreed by a group of farmers, who select a site where they want to create a uniform piece of grazing land. Fallowing thus also has an important function in the livestock production system. Only about $4.24 \%$ of farmers on the study area fallow their land this is due to severe land pressure had led to limited fallowing practices on densely populated areas where land is increasingly cropped on a continuous basis.

\section{CONCLUSIONS}

Socio-economic factors such as a shortage of live stock per house have led to a decline in traditional soil fertility management practices. This will have substantial effects on soil fertility, unless farmers use other measures to add nutrients to their soils. Farmers in the study area are aware of the problems caused by declining soil fertility. There is clear evidence that the productivity of soils in Hursa water shade area will continue to decline if strategic measures are not put in place to manage soil fertility in different soil units to support agricultural land. Application of mineral fertilizers and crop residues are among strategies to be promoted. However, there is a need to promote agro-forestry practices in the area because this will also address community needs for other resources reported to be diminishing.

\section{Conflict of Interest}

All the authors declared no conflict of interest

\section{REFERENCES}

Ajayi, O.C., Franzel, S., Kuntashula, E. and Kwesiga, F. (2003). Adoption of Improved Fallow Technology for Soil Fertility Management in Zambia: Empirical Studies and Emerging Issues. Agroforestry Systems 59: 317-326.
Bekele, W. (2003). Economics of Soil and Water Conservation: Theory and Empirical Application to Subsistence Farming in the Eastern Ethiopian Highlands. Agricultural science Agraria 411: $122-187$

Bekunda, M.A., Bationo, A., and Ssali, H. (1997). Soil Fertility Management in Africa: A Review of Selected Research Trials. In: Buresh R.J., Sanchez P.A. and Calhoun F. (eds.), Replenishing Soil Fertility in Africa. Soil Science Society of America, Madison, Wisconsin, USA, pp. 63-79.

Donova, W.G. (1996). The Role of Inputs and Marketing Systems in the Modernization of Agriculture. Achieving Greater Impact Research Investments in Africa. Fertilizer Research 3:134-67

Kothari, C.R. (2004). Research methodology, New age international Ltd, puublishers. Jaipur (india).

Larson, B.A., Frisvold, G.B. (1996). Fertilizers to support agricultural development in subSaharan Africa. What is needed and why? Food Policy 21: 509-525.

Mitiku, H. (1996). Soil resources of Central Tigray: a case study of selected farms in 7 weredas. In Rural exploratory studies in the central zone of Tigray, Northern Ethiopia. Proceeding of a workshop, pp 19-33. Noragric, Addis Ababa, Ethiopia.

PEDOWS. (1997). Zonal Atlas of West Shewa Planning and Economic Development Office for West Shewa Administrative zone. $1^{\text {st }}$ edition, Ambo, Ethiopia, Printing section of the Ministry of Economic Development and Cooperation.

Quinones, M.A., Borlaug, N.E., Dowswell, C.R. (1998). A fertilizer-based green revolution in Africa and replenishing soil fertility in Africa. Special Publication No.51, Madison, USA.

Shapiro, B.I., Sanders, J.H. (199)8. Fertilizer use in semi-arid West-Africa: profitability and supporting policy. Agriculture System 56: 467-482

Stoorvogel, J.J., Smaling, E.M.A., Janssen, B.H. (1993). Calculating soil nutrientbalances in Africa at different scales. I. Supra-national scale. Fertilizer Research 35: 227-235. 